\title{
Immunohistochemical Study of Vasculogenic Mimicry and Angiogenesis in Melanocytic Tumors of the Eye and the Periocular Area
}

\author{
KONSTANTINOS SPILIOPOULOS ${ }^{1}$, DIMITRIOS PESCHOS ${ }^{2}$, ANNA BATISTATOU ${ }^{3}$, IOANNIS NTOUNTAS ${ }^{4}$, \\ ALEXANDRA PAPOUDOU-BAI ${ }^{3}$, AIKATERINI ZIOGA ${ }^{3}$, NIKI AGNANTIS ${ }^{2}$ and GEORGIOS KITSOS ${ }^{1}$ \\ ${ }^{1}$ Department of Ophthalmology, University Hospital of Ioannina, Ioannina, Greece; \\ ${ }^{2}$ Department of Physiology, University Hospital of Ioannina, Ioannina, Greece; \\ ${ }^{3}$ Department of Pathology, University Hospital of Ioannina, Ioannina, Greece; \\ ${ }^{4}$ First Department of Ophthalmology, 'G. Gennimatas' General Hospital of Athens, \\ University of Athens, Athens, Greece
}

\begin{abstract}
Background/Aim: The ability of a tumor to grow requires a sufficient blood supply. Microvascular density is considered the standard for assessing the neovasculature. Tumor cell vasculogenic mimicry refers to the formation of tumor cell-lined vessels that contribute to tumor neovascularization. The aim of the present work was to study angiogenesis and vasculogenic mimicry in benign and malignant melanocytic tumors of the eye and the periocular region. Patients and Methods: Histological sections from 118 patients were studied. Eighty-eight of the patients had nevi while the remaining 30 had malignant melanomas. Microvascular density was assessed by using antibodies against the endothelial cell markers CD31 and CD34. Vascular-like channels between neoplastic cells, that were not lined by endothelial cells and thus were negative for CD31 and CD34, represented areas of vasculogenic mimicry. Results: Angiogenesis was more pronounced in melanomas compared to melanocytic nevi and was increased in melanomas with high mitotic index and/or epithelioid cell preponderance compared to melanomas with low mitotic index and/or spindle cell predominance. Vasculogenic mimicry was observed in many melanomas, while it was evident in the minority of benign nevi as well. Conclusion: The existence of vasculogenic mimicry in benign nevi might have prognostic implications.
\end{abstract}

Correspondence to: Konstantinos Spiliopoulos, Department of Ophthalmology, University Hospital of Ioannina, Stavros Niarchou Avenue, Ioannina 45500, Greece. Tel: +30 6909719915, e-mail: spiliopk@hotmail.com

Key Words: Angiogenesis, eye, immunohistochemistry, melanocytic, mimicry, tumor, vasculogenic.
Neovascularization is critical for the growth of solid malignant tumors beyond $2 \mathrm{~mm}$ in diameter and for the establishment and development of metastases. Microvascular density (MVD) has been the morphological gold standard to assess the level of neovascularization of solid tumors and has proven to have prognostic significance in several tumors including uveal and cutaneous melanomas (1-5). Different pan-endothelial cell markers have been used for estimation of MVD with CD31 and CD34 being two of the most widely accepted markers. Cluster of differentiation 31 (CD31), also known as platelet endothelial cell adhesion molecule 1 (PECAM-1), is an integral membrane protein and a member of the immunoglobulin superfamily of cell surface receptors. It is expressed by endothelial cells, platelets and most leukocyte subpopulations, as well as by a major population of macrophage/dendritic cell precursors in bone marrow. It makes up a large portion of endothelial cell intercellular junctions and is likely involved in leukocyte migration, angiogenesis and integrin activation. Cluster of differentiation 34 (CD34), also known as hematopoietic progenitor cell antigen CD34, is a transmembrane protein expressed by endothelial cells of blood vessels but not lymphatics (except pleural lymphatics), hematopoietic cells, mesenchymal stem cells, endothelial progenitor cells, mast cells, and dendritic cells. It may play a role in the attachment of stem cells to the bone marrow extracellular matrix or to stromal cells. Studies on tumor angiogenesis focus mainly on malignant tumors even if this process is found in benign tumors as well.

Vasculogenic mimicry (VM) is one of the several different modes of tumor angiogenesis. Angiogenesis is the process of new vessel formation from pre-existing vessels while vasculogenesis refers to blood vessel formation which occurs by a de novo production of endothelial cells from recruited 
Table I. Distribution of benign nevi according to their site and histologic characteristics (upper panel) and distribution of malignant melanomas according to their general type, site, cytologic type, and mitotic activity index (MAI) (lower panel).

\begin{tabular}{|c|c|c|c|c|c|c|c|}
\hline Nevi & 88 & & & & & & \\
\hline Conjuctival & 58 & $(66 \%)$ & Intradermal/Subepithelial & 48 & $(54.5 \%)$ & & \\
\hline Eyelid & 24 & $(27 \%)$ & Compound & 36 & $(41 \%)$ & & \\
\hline Other & 6 & $(7 \%)$ & Junctional & 4 & $(4.5 \%)$ & & \\
\hline Overall melanomas & 30 & & & & & & \\
\hline Uveal melanomas & 23 & $(77 \%)$ & Epithelioid cell & 3 & $(13 \%)$ & Low MAI & $8(27 \%)$ \\
\hline Choroidal & 19 & $(63.5 \%)$ & Spindle cell & 10 & $(43.5 \%)$ & High MAI & $22(73 \%)$ \\
\hline Iris & 3 & $(10 \%)$ & Mixed cell & 10 & $(43.5 \%)$ & & \\
\hline Ciliary body & 1 & $(3.5 \%)$ & & & & & \\
\hline Cutaneous melanomas & 7 & $(23 \%)$ & & & & & \\
\hline
\end{tabular}

endothelial precursor cells. The term angiogenesis is frequently used to describe not only pure angiogenic events, but vasculogenic events as well. $\mathrm{VM}$ is the de novo generation of vascular channels usually by aggressive or metastatic tumor cells and is not considered a strictly vasculogenic process because true vasculogenesis results in de novo formation of endothelial cell-lined vessels (6). These tumor cells express many endothelial and stem cell markers, resulting in a unique phenotype. Periodic acid-Schiff (PAS) stain as well as antibodies against endothelial cell markers CD31 and CD34 have been the gold standard to characterize and study tumor cell VM. VM channels are PAS-positive, CD1 (or CD4)-negative channels. Over the past 2 decades, extensive research has been conducted to study VM with many researchers using in vitro systems with melanoma cell lines. VM has been described in several types of neoplasms including melanomas, glioblastomas and sarcomas, as well as breast, ovarian and liver carcinomas. Little research has been done to study this phenomenon in benign tumors (6).

\section{Patients and Methods}

Tissue specimens. A retrospective review of the pathology database of the University Hospital of Ioannina was conducted after institutional approval, focusing on melanocytic tumors of the eye and the periocular area including lesions of the preauricular area. Tumors had been diagnosed from 2011 to 2015. Pediatric patients (age $<18$ years) were excluded from the study. Histological sections from 154 patients were examined. MVD could be determined in 118 patients. Eighty-eight of the patients had benign nevi, most of which were conjunctival, while the remaining 30 had malignant melanomas, mostly choroidal (Table I). None of the patients had a resection of a dysplastic nevus, probably as a result of the fact that in the majority of our cases the ocular or periocular nevi were resected for cosmetic reasons, rather than for concerns of malignancy based on their morphological characteristics. Moreover, there was no case of primary acquired melanosis. Consecutive histological sections were stained with hematoxylin-eosin and immunohistochemically. Angiogenesis was assessed by studying microvascular density, using antibodies against the endothelial cell markers CD31 and CD34. Vascular-like channels between neoplastic cells, that were not lined by endothelial cells, and thus were negative for $\mathrm{CD} 31$ and $\mathrm{CD} 34$, represented areas of vasculogenic mimicry.

Immunohistochemistry. Intratumoral MVD was determined using immunohistochemical staining performed on a semi-automated immunostainer (BenchMark XT, Ventana Medical Systems, Tucson, AZ, USA) with a biotin-free, multimer-based technology detection system. In summary, $5 \mu \mathrm{m}$ tissue sections were obtained from a representative formalin-fixed, paraffin-embedded block for each patient. Deparaffinization was followed by rehydration, heat induced antigen retrieval and immunohistochemistry with either mouse monoclonal anti-CD31 antibody (clone JC70, 1:50 dilution, Cell Marque, Roclin, CA, USA) or mouse monoclonal anti-CD34 antibody (clone QBEnd/10, 1:70 dilution, Leica, Nussloch, Germany). Diaminobenzidine tetrachloride (DAB) chromogen was used for visualization of the antibody-antigen complex while Harris' Hematoxylin was used as the counterstain.

Assessment of microvascular density. MVD was evaluated by modifying the Weidner's method (7). Briefly, the stained slides were examined at low-power magnification $(\times 100$ magnification) to identify the areas of highest neovascularization (so-called hot spots) of the tumor. In each section, the three most vascular areas were chosen. The degree of either CD31 or CD34 staining and consequently the number of microvessels and the extent of microvascular density expressed as number of microvessels $/ \mathrm{mm}^{2}$ were assessed at 200× magnification using light microscopy (Nikon Labophot Microscope) (Figure 1). The average in the $3 \times 200$ fields (each field measuring $0.6 \mathrm{~mm}^{2}$ ) in each tumor were calculated, and thereafter were referred to as the microvascular density counts. Each endothelial cell or endothelial cell cluster separate from adjacent microvessels was considered a single microvessel. MVD counts were manually estimated. All measurements were performed independently by two observers, and a consensus on any discrepant cases was reached by reassessment.

Cytologic type determination. A modified Callender classification was used in order to classify uveal melanomas into 3 cytologic types (8). In spindle cell melanomas spindle cells constituted $>90 \%$ of total melanoma cells. Mixed cell melanomas were characterized by $>10 \%$ epithelioid cells and $<90 \%$ spindle cells. Epithelioid cell 

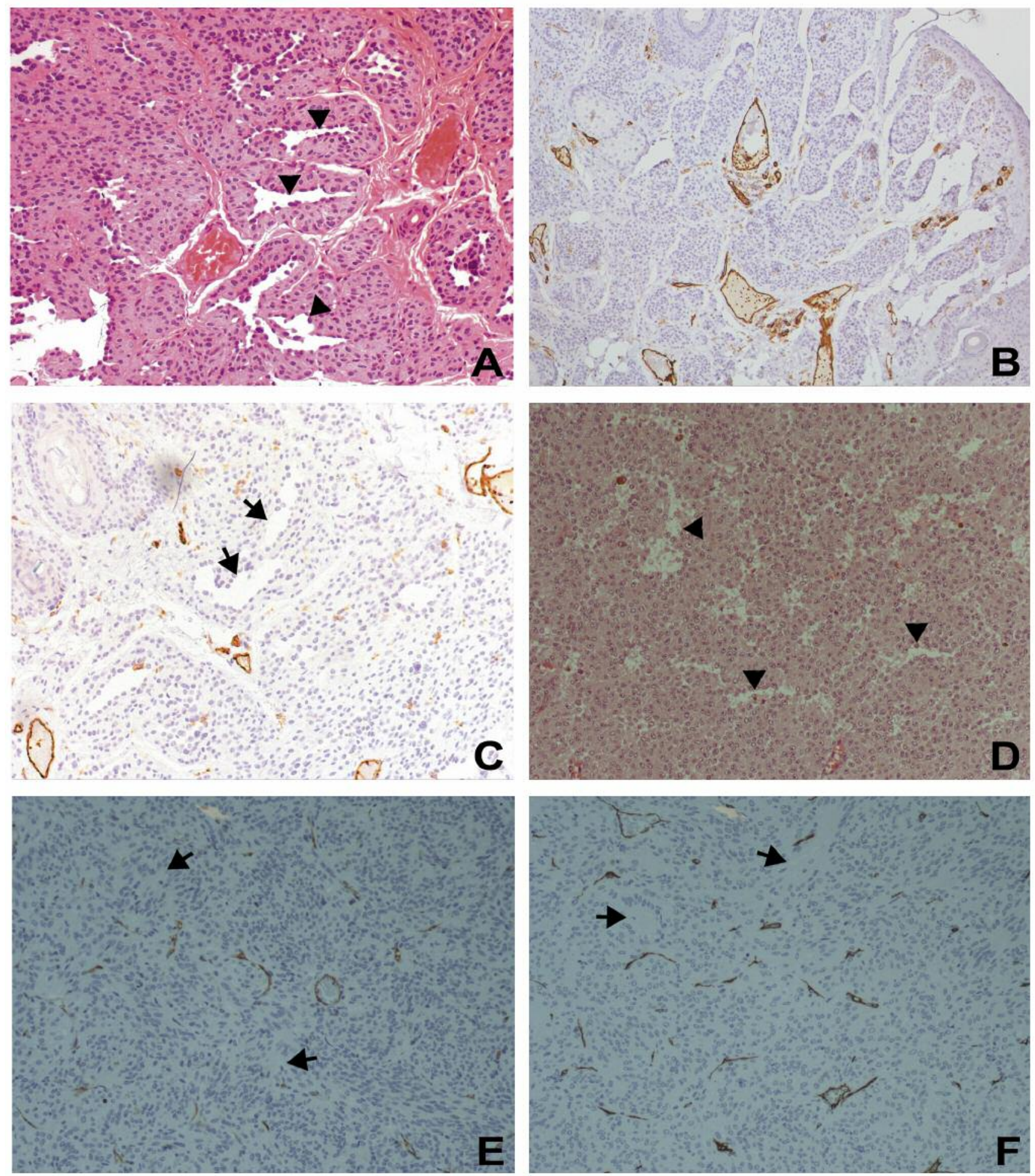

Figure 1. H\&E staining of a benign compound nevus of the periocular skin area (200x) (A), and immunohistochemistry by CD31 staining $(D A B \times 100)(B)$, and CD34 (DAB $\times 200)(C)$ of the same nevus. Vasculogenic mimicry $(V M)$ spaces are illustrated very well at the H\&E stained section (arrowheads). The morphological characteristics of the cells surrounding those spaces are reminiscent of tumor cells rather than endothelial cells. Such spaces are also obvious (but unstained) at the CD34 stained section (arrows). H\&E staining of a mixed cell malignant melanoma of the choroid $(200 \times)(D)$, and immunohistochemistry with staining of CD31 (DAB $\times 200)(E)$ and CD34 $(D A B \times 200)(F)$ of the same melanoma. VM areas are easily recognized at the $H \& E$ stained section (arrowheads) as well as at the CD31 and CD34 stained sections (arrows). 
Table II. Minimum, maximum and mean MVD counts with the usage of antibodies against CD31 or CD34 antigen in benign nevi, malignant melanomas and categories of malignant melanomas as indicated by their general type, cytologic type and mitotic activity index (MAI).

\begin{tabular}{|c|c|c|c|c|c|c|c|c|}
\hline & \multicolumn{2}{|c|}{$\mathrm{CD} 31$} & \multicolumn{2}{|c|}{$\mathrm{CD} 34$} & \multicolumn{4}{|c|}{ Mean MVD counts (vessels $/ \mathrm{mm}^{2}$ ) } \\
\hline & $\begin{array}{c}\text { Minimum } \\
\text { MVD counts } \\
\left(\text { vessels } / \mathrm{mm}^{2}\right)\end{array}$ & $\begin{array}{c}\text { Maximum } \\
\text { MVD counts } \\
\left(\text { vessels } / \mathrm{mm}^{2}\right)\end{array}$ & $\begin{array}{c}\text { Minimum } \\
\text { MVD counts } \\
\left(\text { vessels } / \mathrm{mm}^{2}\right)\end{array}$ & $\begin{array}{c}\text { Maximum } \\
\text { MVD counts } \\
\left(\text { vessels } / \mathrm{mm}^{2}\right)\end{array}$ & CD31 & $p$-Value & CD34 & $p$-Value \\
\hline Benign nevi & 6.0 & 18.0 & 6.0 & 24.0 & $11.4 \pm 3.3$ & & $14.4 \pm 4.4$ & \\
\hline Melanomas (uveal/cutaneous) & 6.0 & 84.0 & 20.0 & 96.0 & $37.5 \pm 18.8$ & 0.000 & $42.1 \pm 19.6$ & 0.000 \\
\hline Uveal Melanomas & 6.0 & 84.0 & 20.0 & 96.0 & $36.4 \pm 20.0$ & 0.000 & $39.9 \pm 20.7$ & 0.000 \\
\hline Cutaneous Melanomas & 22.0 & 64.0 & 32.0 & 70.0 & $40.9 \pm 15.3$ & 0.000 & $49.4 \pm 14.2$ & 0.000 \\
\hline Spindle cell melanomas & 6.0 & 34.0 & 20.0 & 58.0 & $21.6 \pm 7.7$ & & $30.2 \pm 8.3$ & \\
\hline Epithelioid and Mixed-cell melanomas & 22.0 & 84.0 & 24.0 & 96.0 & $46.0 \pm 19.7$ & 0.001 & $46.1 \pm 24.1$ & 0.012 \\
\hline Low MAI melanomas & 18.0 & 50.0 & 22.0 & 58.0 & $29.0 \pm 9.7$ & & $32.3 \pm 11.6$ & \\
\hline High MAI melanomas & 6.0 & 84.0 & 20.0 & 96.0 & $40.5 \pm 20.5$ & 0.043 & $45.7 \pm 20.9$ & 0.027 \\
\hline
\end{tabular}

melanomas were composed almost exclusively from epithelioid cells ( $>90 \%$ epithelioid cells). The great majority of cutaneous melanomas in our study consisted of melanomas with epithelioid cell predominance and this was the reason we excluded them from the statistical analysis. Besides that, cutaneous melanomas are histologically classified in several types not based on spindle cell versus epithelioid cell predominance but based on other characteristics with superficial spreading and nodular melanomas being the two most frequent types (both of them usually having large number of epithelioid cells) $(9,10)$.

Mitotic figure counting. Mitotic activity index (MAI) was used as a measure of mitotic activity. MAI is defined as the number of mitotic figures per 10 high-power fields (HPF). MAI was assessed on hematoxylin-eosin stained tissue sections. For clinical analysis, two MAI subgroups were considered. Low MAI represented $<2$ mitotic figures/10HPF while high MAI corresponded to $\geq 2$ mitotic figures/10HPF. Mitotic figures were counted in areas with good cellularity and in fields with no necrosis or inflammation. Areas with high density of mitotic figures were selected. Counting was carried out in 10 consecutive fields of $0.152 \mathrm{~mm}^{2}$ each resulting in a total surface area of $1.52 \mathrm{~mm}^{2}$ (400x magnification). The mitotic figures were carefully defined to avoid inclusion of apoptotic and necrotic cells.

Assessment of vasculogenic mimicry. Five $\mu \mathrm{m}$ sections were cut from a formalin-fixed, paraffin-embedded tissue block for each patient and stained with hematoxylin and eosin. VM was evaluated on these histological sections (Figure 1). Vascular-like channels between neoplastic cells that were not lined by cells with morphological characteristics of endothelial cells represented areas of VM. Those areas did not stain in corresponding sections that had been used for immunohistochemical staining with antibodies against both CD31 and CD34. VM was qualitatively assessed and was divided into three groups based on the extent of VM observed. Tumors without any areas of VM received a zero (0) score while tumors with few/small and many/large areas of VM scored + and ++ , respectively.
Statistical analysis. Data were analyzed by statistical program SPSS (Statistical Package for the Social Sciences software, version 17.0, Chicago, USA). The statistical significance among MVD means was determined by Student's $t$-test and one-way analysis of variance (ANOVA), followed by post-hoc analyses (Tukey's test) to evaluate the differences between groups (pairwise comparison). Data were expressed as mean \pm standard deviation (S.D.).

\section{Results}

Microvascular density. The mean age of the patients was $43.4 \pm 11.3$ years for the benign nevus group and 59.2 \pm 16.6 years for the malignant melanoma group. The sex distribution was $52.3 \%$ men in the benign nevus group and $43.5 \%$ men in the malignant melanoma group. The intratumoral MVD with anti-CD31 usage ranged from 6 to 84 vessels $/ \mathrm{mm}^{2}$ with a mean of $37.5 \pm 18.8$ vessels $/ \mathrm{mm}^{2}$ in melanomas, while the MVD was less pronounced in benign nevi ranging from 6 to 18 vessels $/ \mathrm{mm}^{2}$ with a mean of $11.4 \pm 3.3$ vessels $/ \mathrm{mm}^{2}(p<0.001)$. Microvessel staining with anti-CD34 antibody was more evident than with anti-CD31 antibody. As a result, the MVD with anti-CD34 usage was higher than with anti-CD31 usage and ranged from 20 to 96 vessels $/ \mathrm{mm}^{2}$ with a mean of $42.1 \pm 19.6$ vessels $/ \mathrm{mm}^{2}$ in melanomas while the MVD in benign nevi ranged from 6 to 24 vessels $/ \mathrm{mm}^{2}$ with a mean of $14.4 \pm 4.4$ vessels $/ \mathrm{mm}^{2}$ $(p<0.001)$ (Table II, Figure 2). MVD was higher in melanomas with an epithelioid cell number $>10 \%$ of the total melanoma cell number, consequently in epithelioid and mixed cell melanomas, compared to spindle cell melanomas, regardless of the type of antibody used, ranging from 22 to 84 vessels $/ \mathrm{mm}^{2}$ with a mean of $46 \pm 19.7$ vessels $/ \mathrm{mm}^{2}$ in the former group and ranging from 6 to 34 vessels $/ \mathrm{mm}^{2}$ with a mean of $21.6 \pm 7.7$ vessels $/ \mathrm{mm}^{2}$ in the latter group, in the case 

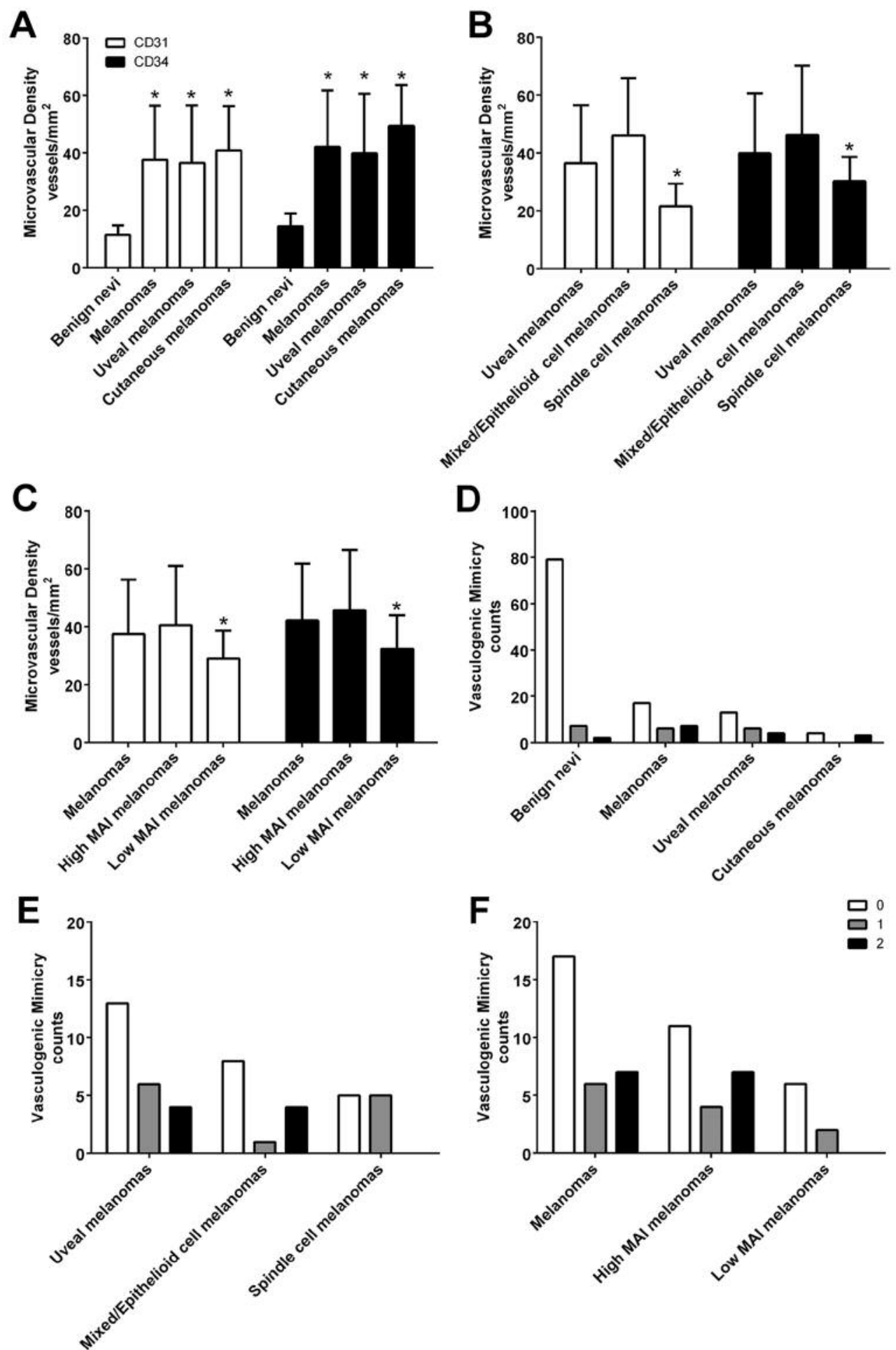

Figure 2. Bar graphs representing microvascular density (MVD) counts and vasculogenic mimicry (VM) extent in different categories. Pairwise comparison of MVD counts between overall melanomas and benign nevi, uveal melanomas and benign nevi, and cutaneous melanomas and benign nevi yielded pvalues of $<0.001$ (A). Comparison of MVD counts between different cytologic types of uveal melanomas revealed that epithelioid cell/mixed melanomas had higher counts than spindle cell melanomas ( $p<0.001$ and $p<0.05$ with anti-CD31 and anti-CD34 usage, respectively) (B). Comparison of MVD counts between melanomas of different mitotic activity indices (MAIs) revealed that high MAI melanomas had higher counts than low MAI melanomas $(p<0.05)(C)$. Distribution of VM extent in benign nevi, overall melanomas, uveal melanomas and cutaneous melanomas $(D)$. Distribution of VM extent in uveal melanomas and melanomas of different cytologic type $(E)$. Distribution of VM extent in overall melanomas and melanomas of different MAI $(F)$. 
Table III. Vasculogenic mimicry (VM) extent in benign nevi, malignant melanomas and categories of malignant melanomas as indicated by their general type, cytologic type and mitotic activity index (MAI).

\begin{tabular}{lcccc}
\hline & VM 0 & VM+ & VM++ & Sum \\
\hline Benign nevi & 79 & 7 & 2 & 88 \\
Melanomas (uveal/cutaneous) & $90 \%$ & $8 \%$ & $2 \%$ & \\
& 17 & 6 & 7 & 30 \\
Uveal Melanomas & $57 \%$ & $20 \%$ & $23 \%$ & \\
& 13 & 6 & 4 & 23 \\
Cutaneous Melanomas & $57 \%$ & $26 \%$ & $17 \%$ & \\
Epithelioid and Mixed-cell melanomas & 4 & 0 & 3 & 7 \\
Spindle cell melanomas & $87 \%$ & $0 \%$ & $43 \%$ & \\
& $61 \%$ & $8 \%$ & $31 \%$ & 13 \\
High MAI melanomas & 5 & 5 & 0 & 10 \\
& $50 \%$ & $50 \%$ & 0 & \\
Low MAI melanomas & 11 & 4 & 7 & 22 \\
& $50 \%$ & $18 \%$ & $32 \%$ & \\
& 6 & 2 & 0 & 8 \\
& $75 \%$ & $25 \%$ & 0 & \\
\hline
\end{tabular}

of anti-CD31 antibody $(p<0.001)$. Please, see Table II and Figure 2 for results with anti-CD34 usage. Melanomas with high MAI had increased MVD in comparison to melanomas with low MAI, an outcome that was statistically significant (Table II, Figure 2). Tumor size was not among the parameters tested for MVD differences because the great majority of uveal melanomas had either medium or large size and only a few melanomas had small size (tumor size defined according to a widely accepted protocol) (8).

Vasculogenic mimicry. Vasculogenic mimicry was observed in 13 out of 30 melanomas $(43 \%)$ while it was much less frequent in benign nevi, being found in only 9 out of 88 nevi (10\%), a difference that was statistically significant (Chisquare test, $\left.\chi^{2}=16.17, p<0.001\right)$. Even if the frequency of VM was similar in melanomas irrespective their histologic type, we observed that there were differences in the extent of VM with epithelioid cell melanomas and mixed cell melanomas having more extended areas of VM compared to spindle cell melanomas. Moreover, high MAI melanomas had increased VM frequency and extent compared to low MAI melanomas (Table III, Figure 2). These observations were not confirmed with statistical analysis due to the small size of our sample.

\section{Discussion}

Angiogenesis is a crucial process in normal physiology, but it is also an important pathogenic process in both benign and malignant disease. The induction of an adequate tumor vasculature in response to increasing request of oxygen and nutrient supply is of paramount importance for tumor growth.

Previous studies on MVD differences in melanocytic lesions focused primarily on cutaneous malignant melanomas and nevi and found that MVD is higher in cutaneous malignant melanomas than in benign or dysplastic nevi (11-14). We found that MVD is also higher in uveal melanomas in comparison to benign nevi of the eye and the periocular area. The median MVD count of 42.1 vessels $/ \mathrm{mm}^{2}$ in uveal melanomas in our study (anti-CD34 antibody) is lower than the median MVD count of 40 vessels/0.313 $\mathrm{mm}^{2}$ in a previous study wherein 162 enucleation specimens from patients with uveal melanomas had been examined (anti-CD34 antibody) (3). The difference between the two studies might be partially attributable to differences in methodology used. There is an association of high MVD and epithelioid cell predominance in uveal melanomas (3). Similarly, epithelioid and mixed cell melanomas had higher MVD than spindle cell melanomas in our study, a reasonable finding given the fact that the former type of melanomas has worse prognosis than the latter, and high MVD is an adverse prognostic feature of uveal melanomas. Additionally, the positive correlation we found between the mitotic activity and the MVD is also reasonable taking into account the enhanced aggressiveness of high MAI tumors.

Since 1999, when Maniotis, Hendrix and colleagues first described the phenomenon of vasculogenic mimicry, a lot of research has been conducted to clarify the molecular mechanisms that are implicated at the formation of these tumor cell-lined vascular networks. VM has been studied in malignant tumors, mostly melanomas, with $45 \%$ of primary uveal melanomas having areas of VM according to the prototype study performed by Maniotis et al. (15). VM networks were detected in situ as well in 34\% of tumor primary sites in patients with human cutaneous melanomas (16) indicating that VM network prevalence in human cutaneous and uveal melanomas is probably similar. Our findings are in accordance with the aforementioned studies. Forty-three percent of our uveal melanoma patients exhibited areas of VM at the primary tumor site.

The presence of VM in melanomas, both uveal and cutaneous, is a poor prognostic indicator leading to shorter survival rates (16-21). The same applies to most of the other malignant tumors studied (21). Therefore, our observation that melanomas with more aggressive histologic features have more extended areas of VM is not unexpected.

Importantly, $10 \%$ of benign nevi in our patients included areas of VM. The presence of VM in some nevi is a very interesting finding, given the paucity of relevant studies in the English literature. Only one case report and two small case series were found in our Pubmed search. Melanocyte- 
lined 'pseudovascular spaces' were observed in three benign pigmented nevi (22), in three benign melanocytic nevi (23) as well as in one benign nevus (24). In our cases the presence of VM was not associated with atypical features indicating that probably it is not associated with malignant potential.

Scientists have been trying to find methods in order to recognize which nevi may progress to melanoma. Modern molecular methods, including genetic markers, cytokines, and proliferation indices, are all undergoing study (25-29). Most of the nevi in our study were conjuctival. Of note, most conjuctival melanomas arise from primary acquired melanosis with atypia, while a significant portion (5-25\%) arises from a pre-existing nevus $(30,31)$. However, the risk of malignant transformation of a conjuctival nevus is low, less than $1 \%$ (31). Similarly, a significant portion of cutaneous melanomas, approximately one out of four, arise from a pre-existing nevus (32) even if nevi, including dysplastic nevi, have a low risk of malignant transformation (29, 33-35). Dysplastic nevi and aypical moles are acquired melanocytic lesions of the skin whose clinical and histologic definitions are controversial and still evolving. Further research on benign and particularly dysplastic nevi is needed to clarify the prevalence of VM in these lesions and discover whether this finding has any prognostic implications, increasing the risk of transformation to malignant melanomas.

\section{References}

1 Weidner N, Semple JP, Welch WR and Folkman J: Tumor angiogenesis and metastasis-correlation in invasive breast carcinoma. N Engl J Med 324(1): 1-8, 1991.

2 Foss AJ, Alexander RA, Jefferies LW, Hungerford JL, Harris AL and Lightman S: Microvessel count predicts survival in uveal melanoma. Cancer Res 56: 2900-2903, 1996.

3 Makitie T, Summanen P, Tarkkanen A and Kivela T: Microvascular density in predicting survival of patients with choroidal and ciliary body melanoma. Invest Ophthalmol Vis Sci 40: 2471-2480, 1999

4 Nico B, Benagiano V, Mangieri D, Maruotti N, Vacca A and Ribatti D: Evaluation of microvascular density in tumors: pro and contra. Histol Histopathol 23: 601-607, 2008.

5 Depasquale I and Thompson WD: Microvessel density for melanoma prognosis. Histopathol 47(2): 186-194, 2005.

6 Spiliopoulos K, Peschos D, Batistatou A, Ntountas I, Agnantis $\mathrm{N}$ and Kitsos G: Vasculogenic Mimicry: Lessons from Melanocytic Tumors. In Vivo 29(3): 309-317, 2015.

7 Weidner $\mathrm{N}$ : Current pathologic methods for measuring intratumoral microvessel density within breast carcinoma and other solid tumors. Breast Cancer Res Treat 36(2): 169-180, 1995.

8 Grossniklaus HE, Finger PT, Harbour JW and Kivela T: Protocol for the Examination of Specimens From Patients With Uveal Melanoma. College of American Pathologists. Protocol web posting date: January 2016.
9 Smoller BR, Balch C, Balzer BL, Crowson AN, Didolkar M, Lazar A, McNiff JM, Perry RR, Prieto VG, Rao P, Smith MT, Wick MR and Frishberg DP: Protocol for the Examination of Specimens From Patients With Melanoma of the Skin. College of American Pathologists. Protocol web posting date: January 2016.

10 LeBoit PE, Burg G, Weedon D and Sarasin A: World Health Organization Classification of Tumours. Pathology and Genetics. Skin Tumours. Lyon, IARCPress, pp. 66-69, 2006.

11 Einspahr JG, Thomas TL, Saboda K, Nickolof BJ, Warneke J, Curiel-Lewandrowski C, Ranger-Moore J, Duckett L, Bangert J, Fruehauf JP and Alberts DS: Expression of vascular endothelial growth factor in early cutaneous melanocytic lesion progression. Cancer 110(11): 2519-2527, 2007.

12 Zidlik V, Brychtova S, Uvirova M, Ziak D and Dvorackova J: The Changes of Angiogenesis and Immune Cell Infiltration in the Intra- and Peri-Tumoral Melanoma Microenvironment. Int J Mol Sci 16(4): 7876-7889, 2015.

13 Tu YT, Tao J, Liu YQ, Li Y, Huang CZ, Zhang XB and Lin Y: Expression of endothelial nitric oxide synthase and vascular endothelial growth factor in human malignant melanoma and their relation to angiogenesis. Clin Exp Dermatol 31(3): 413418, 2006.

14 Vacca A, Ribatti D, Roncali L, Lospalluti M, Serio G, Carrel S and Dammacco F: Melanocyte Tumor Progression Associated with Changes in Angiogenesis and Expression of the 67Kilodalton Laminin Receptor. Cancer 72(2): 455-461, 1993.

15 Maniotis AJ, Folberg R, Hess A, Seftor EA, Gardner LM, Pe'er J, Trent JM, Meltzer PS and Hendrix MJ: Vascular channel formation by human melanoma cells in vivo and in vitro: vasculogenic mimicry. Am J Pathol 155(3): 739-752, 1999.

16 van Beurden A, Schmitz RF, van Dijk CM and Baeten CI: Periodic acid Schiff loops and blood lakes associated with metastasis in cutaneous melanoma. Melanoma Res 22(6): 424429, 2012.

17 Folberg R, Hendrix MJ and Maniotis AJ: Vasculogenic mimicry and tumor angiogenesis. Am J Pathol 156(2): 361-381, 2000.

18 Makitie T, Summanen P, Tarkkanen A and Kivela T: Microvascular Loops and Networks as Prognostic Indicators in Choroidal and Ciliary Body Melanomas. J Natl Cancer Inst 91(4): 359-367, 1999.

19 Folberg R, Rummelt V, Parys-Van Ginderdeuren R, Hwang T, Woolson RF, Pe'er J and Gruman LM: The prognostic value of tumor blood vessel morphology in primary uveal melanoma. Ophthalmology 100(9): 1389-1398, 1993.

20 Warso MA, Maniotis AJ, Chen X, Majumdar D, Patel MK, Shilkaitis A, Gupta TK and Folberg R: Prognostic significance of periodic acid-Schiff-positive patterns in primary cutaneous melanoma. Clin Cancer Res 7(3): 473-477, 2001.

21 Cao Z, Bao M, Miele L, Sarkar FH, Wang Z and Zhou Q: Tumour vasculogenic mimicry is associated with poor prognosis of human cancer patients: a systemic review and meta-analysis. Eur J Cancer 49(18): 3914-3923, 2013.

22 Modlin RL, Gottlieb B, Taylor C and Rea TH: Identification of cells lining pseudovascular spaces of benign pigmented nevi. Am J Dermatopathol 6 Suppl: 25-29, 1984.

23 Lee KH, Han YW and Park CJ: Three Cases of Melanocytic Nevi with Pseudovascular Spaces. Korean J Dermatol 45(1): 9093, 2007. 
24 Demitsu T, Kakurai M, Yamada T, Kiyosawa T and Yaoita H: The vascular space-like structure in melanocytic nevus is not an injection artifact: report of a case and an experimental study. J Dermatol 25(3): 143-149, 1998.

25 Pierard GE, Pierard-Franchimont C and Delvenne P: Simulants of malignant melanoma. Onc Rev 9(1): 278, 2015.

26 Lebe B, Pabuccuoglu U and Ozer E: The significance of Ki-67 proliferative index and cyclin D1 expression of dysplastic nevi in the biologic spectrum of melanocytic lesions. Appl Immunohistochem Mol Morphol 15(2): 160-164, 2007.

27 Clarke LE: Dysplastic nevi. Clin Lab Med 31(2): 255-265, 2011.

28 Roh MR, Eliades P, Gupta S and Tsao H: Genetics of melanocytic nevi. Pigment Cell Melanoma Res 28(6): 661-672, 2015.

29 Hussein MR: Melanocytic dysplastic naevi occupy the middle ground between benign melanocytic naevi and cutaneous malignant melanomas: emerging clues. J Clin Pathol 58(5): 453456, 2005.

30 Kanski JJ and Bowling B: Clinical Ophthalmology: A Systematic Approach (8th ed.). Edinburgh, Elsevier, pp. 474, 2015.
31 Zembowicz A, Mandal RV and Choopong P: Melanocytic Lesions of the Conjuctiva. Arch Pathol Lab Med 134: 17851792, 2010.

32 Sam AH and Theo JTH: Rapid Medicine. (1st ed.) Malden, Massachusetts, Wiley-Blackwell, pp. 192, 2003.

33 Tsao H, Bevona C, Goggins W and Quinn T: The transformation rate of moles (melanocytic nevi) into cutaneous melanoma: a population based-estimate. Arch Dermatol 139(3): 282-288, 2003.

34 Cyr PR: Atypical Moles. Am Fam Physician 78(6): 735-740, 2008.

35 Perkins A and Duffy RL: Atypical Moles: Diagnosis and management. Am Fam Physician 91(11): 762-767, 2015.

Received December 12, 2016

Revised February 1, 2017

Accepted February 2, 2017 